\title{
Visual function after penetrating keratoplasty for keratoconus: a prospective longitudinal evaluation
}

\author{
Arun Brahma, Fergal Ennis, Robert Harper, Alan Ridgway, Andrew Tullo
}

\begin{abstract}
Aims-To evaluate visual function and vision specific health status in patients undergoing penetrating keratoplasty for keratoconus.

Methods-A prospective longitudinal study measuring $\log$ MAR visual acuity, contrast sensitivity, disability glare, binocular visual field, stereoacuity, and subjective visual function (VF-14) was conducted on 18 patients with keratoconus undergoing penetrating keratoplasty (PK), including six patients who had already had PK in the fellow eye. Data were collected preoperatively and at 3,9 , and 18 months after surgery.

Results-Within 3 months of surgery there was significant improvement in aided visual acuity, contrast sensitivity, and stereoacuity $(p<0.05)$; disability glare $(p<0.05)$ no longer had a significant detrimental effect on these variables. VF-14 score improved significantly throughout the postoperative period $(p<0.05)$. There was significant correlation of the VF-14 score with aided visual acuity, binocular visual field, and stereoacuity. Postoperative astigmatism $(<4 \mathrm{D} v>4 \mathrm{D})$ did not affect the VF-14 score significantly.

Conclusions-There is substantial and rapid improvement in visual function and vision specific health status in keratoconic patients as a result of uncomplicated penetrating keratoplasty.

(Br f Ophthalmol 2000;84:60-66)
\end{abstract}

Keratoconus is the principal indication for penetrating keratoplasty in young adults and graft survival in this condition has been used as a yard stick against which to measure the outcome of corneal transplantation for other conditions. ${ }^{1}$

Snellen visual acuity has long served as the primary visual function test of surgical success. However, some patients report limitations to vision despite a clear graft and good corrected visual acuity. Over the past two decades there has been mounting evidence that aspects of visual function other than acuity are impaired in those who have media opacities (corneal scarring and cataracts) and irregularities of the cornea. ${ }^{2-5}$

At the same time, detailed visual function assessments, which measure self rated disability, have been developed for patients with cataract and their response to surgery. ${ }^{6-9}$ Very few such studies have been reported on patients who have undergone penetrating keratoplasty; most are retrospective and use a single point of time for assessment. ${ }^{5-11}$ The purpose of this study was to undertake a prospective longitudinal evaluation of visual function and vision specific health status in patients undergoing penetrating keratoplasty for keratoconus.

\section{Methods}

Keratoconic patients undergoing penetrating keratoplasty from January 1996 to March 1996 under the care of two corneal surgeons (AT and $\mathrm{AR}$ ) were invited to participate in this study. The diagnosis of keratoconus was based on slit lamp examination, computerised video keratotopography, and refraction. The study had approval from the local ethics committee and all subjects gave informed consent. $\mathrm{Pa}-$ tients were eligible for the study if they were over the age of 16 years, willing to attend assessments in addition to the routine clinical visits, and understood English. Indications for surgery were the inability to achieve good vision with or intolerance of contact lens. This study was not masked.

Donor corneas were provided by the United Kingdom Corneal Transplant Service eye banks. The donor corneas were stored in organ culture at $34^{\circ} \mathrm{C}$ and were subject to quality assessment and allocation procedures described elsewhere. ${ }^{12}$

The surgery was standardised as far as possible. All patients had preoperative biometry to establish vitreous cavity length $(<16 \mathrm{~mm}$, the donor trephine was greater than the recipient by $0.25 \mathrm{~mm}$; if $>16 \mathrm{~mm}$ the donor and recipient trephines were the same size). ${ }^{13}$ All recipient and donor corneas were trephined with hand held trephines. All corneas were sutured using interrupted 10.0 nylon sutures. Postoperative treatment was a combination of topical antibiotic and steroid, the frequency, duration and the strength of which depended on each individual patient. Three months after surgery, selective suture removal was initiated to reduce astigmatism. At the time of the final assessment (18 months) all sutures had been removed.

Patients were assessed for the study preoperatively and postoperatively at 3, 9, and 18 months. All assessments were undertaken on both eyes of each patient by one examiner (AB) in the same clinical area and using the same equipment for each visit. Experienced optometrists performed all refractions. Visual function tests were assessed using the best spectacle correction for all postoperative assessments. The vision specific health status questionnaire (VF-14) score was based on corrected refracted error (contact lens) preoperatively, uncorrected refractive error at 3 and 9 months, 
and spectacle/contact lens correction for the 18 month assessment.

VISUAL FUNCTION TESTS

Visual acuity

A Bailey-Lovie $(\log M A R)^{14}$ front illuminated chart was used to measure visual acuity at 3 metres. The front luminance was 100 candela/ $\mathrm{m}^{2}$. Visual acuity was recorded in $\log$ MAR units using the method recommended by Bailey et al. ${ }^{15}$ A score of 0.00 and 1.00 are equivalent to Snellen acuity of $6 / 6$ and $6 / 60$ respectively.

Contrast sensitivity

The Pelli-Robson low contrast letter charts ${ }^{16}$ (Clement Clarke International Ltd) were used for assessing contrast sensitivity in this study, because it had specificity/sensitivity and reliability comparable with other contrast sensitivity tests $^{17}$ and was quick and simple to implement. The chart was used at 1 metre, as per current test instructions ${ }^{18}$ although 3 metres was the original test distance recommended by Pelli et al. ${ }^{16}$ The chart was illuminated to 100 candela $/ \mathrm{m}^{2}$.

\section{Disability glare testing}

The brightness acuity tester (BAT) ${ }^{19}$ is a hand held instrument that consists of a hemispheric bowl (diameter $60 \mathrm{~mm}$ ) with an internally illuminated surface and the glare source (shielded light bulb located superiorly). The subject held the device to the eye and viewed the chart through a central $12 \mathrm{~mm}$ aperture. Subjects wore their refractive correction (spectacles, trial frames, or contact lenses) during the testing procedure. Visual acuity and contrast sensitivity were measured with and without the BAT at the brightest setting (1370 candela/ $\mathrm{m}^{2}$ ). A different chart was used to avoid memorisation.

\section{Binocular visual field}

The visual field was measured with the Esterman test ${ }^{20}$ of the Humphrey field analyser (HFA) 630 (Humphrey Instruments Inc, San Leandro, CA, USA). Binocular testing was carried out and scored according to the manufacturer's recommendations.

\section{Stereopsis}

A quantitative assessment of stereopsis was made using the TNO random dot stereograms (Lameris Ootech, Groenakan, Netherlands). ${ }^{21}$ For each subject the presence of stereopsis was ascertained using plates I-III. If present, the degree of stereopsis was quantified using plates V-VII. Subjects used their optimum refractive correction. Stereoacuity was graded between 0 and 8 , depending on the above plates $(0=$ no stereopsis; 1 = gross stereopsis; $2=$ plate $2 ; 3=$ plate $3 ; 4=480$ seconds; $5=360$ seconds; $6=$ 240 seconds; $7=120$ seconds; $8=60$ seconds (disparity).

Vision specific health status

The VF-14 ${ }^{22}$ (a visual functioning index) was used to give a measure of vision specific health status. Final score ranges between 0 (unable to
Table 1 Demographic data of all patients completing the study

\begin{tabular}{lrll}
\hline & No & Age range (years) & Mean age (years) \\
\hline Male & 12 & $20.3-61.2$ & 32.4 \\
Female & 6 & $22.0-36.2$ & 30.3 \\
All & 18 & $20.3-61.2$ & 31.7 \\
\hline
\end{tabular}

do any of the activities) and 100 (able to do all activities without any impairment).

Other information collected included demographic data and refractive error (mean spherical equivalent).

Statistical analyses were performed on the collected data using SPSS version 7, 1995 (SPSS Inc, USA) on a PC (IBM compatible). Non-parametric statistical tests were used, as the data were not normally distributed except for the age of the subjects.

\section{Results}

Eighteen consecutive keratoconic patients agreed to participate in the study. Of the 18 patients, one needed additional sutures due to dehiscence of the wound in the immediate postoperative period (data included). All assessments were conducted within 1 week of the appropriate postoperative date. At the 18 month assessment period all sutures had been removed, all corneal grafts were clear, and there had been no episodes of immunological rejection. Assessments lasted approximately 1 hour per patient on each occasion.

Demographic data of the patients are given in Table 1. There were six females and 12 males. All patients had bilateral disease of varying severity. Six of the 18 patients had previously undergone penetrating keratoplasty in the fellow eye.

\section{VISUAL FUNCTION TESTS}

Visual acuity

LogMAR visual acuity scores at each assessment for the operated eyes are graphically shown in Figure 1. The median values for the four assessments for the operated eyes were $0.76,0.24,0.11$, and 0.07 . The preoperative median $\log$ MAR visual acuity was low but at the 3 months' assessment visual acuity had significantly improved ( $p=0.002$, Wilcoxon test). There was further significant improvement between 3 and 9 months $(p=0.044)$ and this improvement in vision continued between the 9 and 18 months but not significantly ( $\mathrm{p}=$ $0.168)$. The most significant improvement

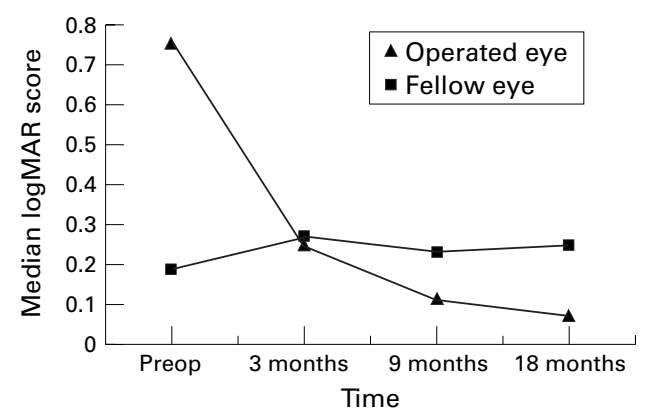

Figure 1 The median corrected $\log M A R$ visual acuity scores for the operated and fellow eyes. 
Table 2 LogMAR, contrast sensitivity and disability glare data for the operated and fellow eyes

\begin{tabular}{|c|c|c|c|c|c|c|}
\hline \multicolumn{3}{|l|}{ Operated eye } & \multirow[b]{2}{*}{$n=18$} & \multicolumn{3}{|c|}{ Fellow eye } \\
\hline Median & Min & $\operatorname{Max}$ & & Median & Min & $\operatorname{Max}$ \\
\hline \multicolumn{7}{|c|}{ LogMAR visual acuity (unaided vision) } \\
\hline $0.76(1.14)$ & $0.1(0.72)$ & $1.77(1.78)$ & Preop & 0.19 & -0.20 & 0.94 \\
\hline $0.24(0.74)^{\star}$ & $0.0(0.38)$ & $0.72(1.26)$ & 3 months & 0.27 & -0.18 & 0.80 \\
\hline $0.11(0.7)$ & $0.0 \quad(0.20)$ & $1.06(1.22)$ & 9 months & 0.23 & -0.20 & 1.27 \\
\hline $0.07(0.8)$ & $-0.2(0.0)$ & $1.10(1.32)$ & 18 months & 0.25 & -0.20 & 1.36 \\
\hline \multicolumn{7}{|c|}{ Contrast sensitivity (unaided contrast sensitivity) } \\
\hline $0.82(0.65)$ & $0 \quad(0.0)$ & $1.50(1.50)$ & Preop & 1.55 & 0.9 & 2.00 \\
\hline $1.62(1.46)^{\star}$ & $1.30(0.85)$ & $1.85(1.70)$ & 3 months & 1.50 & 0.75 & 1.80 \\
\hline $1.80(1.50)$ & $1.50(1.00)$ & $1.95(1.80)$ & 9 months & 1.50 & 0.75 & 1.90 \\
\hline $1.75(1.45)^{\star}$ & $1.40(0.90)$ & $2.10(1.80)$ & 18 months & 1.55 & 0.75 & 2.00 \\
\hline \multicolumn{7}{|c|}{ Disability glare, $\log$ MAR } \\
\hline $1.10 \mathrm{~s}$ & -0.18 & 2.00 & Preop & 0.26 & -0.18 & 0.94 \\
\hline 0.21 & 0.00 & 0.68 & 3 months & 0.26 & -0.20 & 0.84 \\
\hline 0.10 & -0.08 & 0.90 & 9 months & 0.29 & -0.20 & 1.18 \\
\hline 0.09 & -0.20 & 0.72 & 18 months & 0.24 & -0.20 & 1.28 \\
\hline \multicolumn{7}{|c|}{ Disability glare, contrast sensitivity } \\
\hline $0.65 \rrbracket$ & 0.00 & 1.40 & Preop & 1.67 & 0.90 & 1.80 \\
\hline 1.62 & 1.15 & 1.80 & 3 months & 1.60 & 0.60 & 1.85 \\
\hline 1.75 & 1.35 & 1.90 & 9 months & 1.42 & 0.80 & 1.80 \\
\hline 1.65 & 1.20 & 2.00 & 18 months & 1.55 & 0.15 & 2.05 \\
\hline
\end{tabular}

^Significant change compared with previous assessment, Wilcoxon test; §significant effect preoperatively only.

occurred within 3 months of surgery. Overall, the visual acuity improved over the duration of the study period ( $\mathrm{p}=0.000$, Friedman test). The unaided vision for the operated eye improved most significantly within the first 3 months (Wilcoxon test) and throughout the 18 months (Friedman test). The data are shown in Table 2.

The median visual acuities of the fellow eyes were $0.19,0.27,0.23$, and 0.25 at the four assessments and did not vary significantly over the 18 months ( $p=0.746$, Friedman test). Data for the fellow eye are shown in Table 2 and Figure 1 to aid comparison with the operated eye.

\section{Contrast sensitivity}

Contrast sensitivity scores for the operated and fellow eyes are illustrated in Table 2 and Figure 2. For the operated eyes, the improvement in contrast sensitivity parallels $\log M A R$ scores. The median values for the four assessments for the operated eyes were $0.825,1.625,1.80$, and 1.75. There was significant change between the preoperative and 3 months assessment $(\mathrm{p}=$ 0.000 , Wilcoxon test) and between 3 and 9 months $(\mathrm{p}=0.001)$, but not between 9 and 18 months $(p=0.242)$. There were significant correlations ( $p<0.05$, Spearman) between the visual acuity and contrast sensitivity scores preoperatively and at 18 months but not at the other assessments. There was no significant

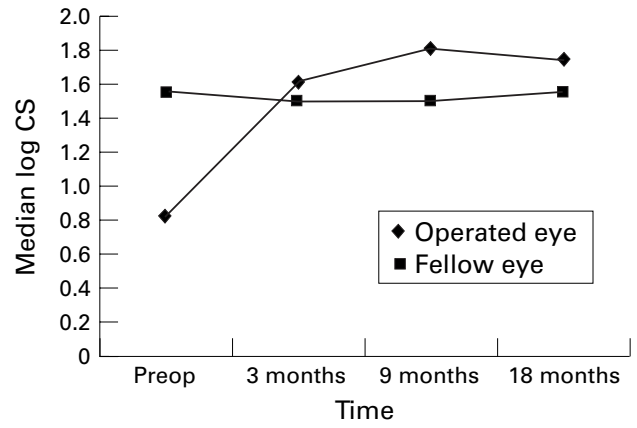

Figure 2 Median corrected contrast sensitivity scores for the operated and fellow eyes. change in the contrast sensitivity scores in the fellow eyes for the four assessments (median values were $1.55,1.50,1.50$ and $1.55: \mathrm{p}=$ 0.546 , Friedman test).

\section{Disability glare}

Visual acuity and contrast sensitivity scores using the BAT are illustrated in Figures 1 and 2 , respectively. Glare only significantly reduced visual acuity preoperatively $(\mathrm{p}=0.033$, median preoperative difference $=-0.088$, Wilcoxon test). There was no significant difference at 3 months or thereafter. Preoperative contrast sensitivity function was similarly significantly reduced $(\mathrm{p}=0.000$, median difference $=$ $0.125)$. Thus, only before penetrating keratoplasty did the glare source have a significant detrimental effect on visual acuity and contrast sensitivity. Data for the fellow eye are shown in Table 2 for comparison.

\section{Esterman fields}

The binocular Esterman field of vision scores did not alter significantly over the 18 months assessment period ( $p=0.441$, Friedman test). The median and the range of scores are tabulated in Table 3.

\section{Stereopsis}

Stereoacuity based on the TNO test improved significantly ( $p=0.009$, Friedman test) over the duration of the study. Stereoacuity results are shown in Table 3 (preop median $=0,18$ months median $=5$ ). The most significant change occurred after surgery at the 3 months assessment ( $p=0.002$, Wilcoxon), further significant improvement occurred between 3 and 9 months ( $p=0.016$, Wilcoxon) but there was no further significant improvement between 9 and 18 months ( $p=0.12$, Wilcoxon). The levels of stereopsis at the initial preoperative and the final postoperative assessment showed significant correlation (Spearman) with visual acuity $(p=007 / p=0.013)$ and with contrast sensitivity $(\mathrm{p}=0.006 / \mathrm{p}=0.048)$.

Table 3 Descriptive data on binocular visual field, stereoacuity, mean spherical equivalent, anisometropia, and $V F-14$ questionnaire

\begin{tabular}{lccc}
\hline & Median & Minimum & Maximum \\
\hline Esterman binocular visual field & & \\
Preop & 100 & 86 & 100 \\
3 months & 99.5 & 97 & 100 \\
9 months & 100 & 96 & 100 \\
18 months & 100 & 90 & 100 \\
TNO stereoacuity (see text for grading) & \\
Preop & 0 & 0 & 4 \\
3 months & 1.5 & 0 & 8 \\
9 months & 3.5 & 0 & 7 \\
18 months & 5 & 0 & 8 \\
Mean spherical equivalent (D) & & \\
Preop (n=10) & -4.00 & -18.25 & 4.38 \\
3 months & -3.25 & -7.63 & 5.25 \\
9 months & -4.50 & -9.20 & 5.13 \\
18 months & -3.75 & -10.0 & 4.00 \\
Anisometropia & \multicolumn{3}{|c}{} \\
3 months & 1.75 & -3.5 & 16.63 \\
9 months & 0.50 & -7.25 & 16.25 \\
18 months & 0.12 & -7.38 & 17.25 \\
VF-14 questionnaire & \multicolumn{3}{l}{} \\
Preop & 72.9 & 14.58 & 100 \\
3 months & 87.9 & 35.4 & 100 \\
9 months & 90.9 & 52.1 & 100 \\
18 months & 97.2 & 52.1 & 100 \\
\hline
\end{tabular}


Refractive error

Mean spherical equivalent (MSE) values of the refractive error are given in Table 3. There was a significant reduction in the MSE in the postoperative period between 3 and 18 months ( $p$ $=0.008$, Friedman). The preoperative MSE data were not included in the statistical analysis because accurate refraction could not be performed in eight of the 18 operated eyes, as a result of severe distortion of the reflex but the available data are tabulated in Table 3 . Preoperative MSE of the 10 patients showed a wide range $(>22.5 \mathrm{D})$, but this reduces to $12.88 \mathrm{D}$ at 3 months, $14.33 \mathrm{D}$ at 9 months, and $14 \mathrm{D}$ at 18 months.

Anisometropia (difference between MSE of both eyes) for each of the postoperative assessments is tabulated in Table 3.

VF-14

The VF-14 questionnaires were scored by the patients without optical aids except at the preoperative and the 18 month assessments because all patients had not obtained appropriate correction during the first postoperative year.

Subjective visual function scores ranged from 14.58 to 100 before surgery and from 52 to 100 at 18 months (Table 3 ). The median scores for the four assessments were 72.9, 87.9, 90.9, and 97.2. The improvement in the VF-14 score is significant over the 18 month period ( $\mathrm{p}$ $=0.012$, Friedman) but the improving scores between each of the assessments did not reach significance. Data on the ability of patients to perform specific tasks in the questionnaire were analysed for driving and hand-eye coordinating tasks. Preoperatively, 90.9\% patients who could drive did not do so because of lack of confidence in their vision; this decreased to $54.45 \%$ at 18 months. The VF-14 question that assessed hand-eye coordination (threading a needle, carpentry, etc) did not reach significance over the 18 months ( $p=0.069$, Friedman) but nearly reached significance when the preoperative and the 18 months were compared ( $p=0.051$, Wilcoxon).

\section{Correlation between VF-14 and visual function tests}

Correlation of the visual function in the operated eye (logMAR, contrast sensitivity, binocular field, and stereoacuity) with the improvement in the VF-14 scores were examined for each assessment (Table 4). The $\log$ MAR acuity of the operated eye correlates significantly with VF-14 scores at the last two assessments. Contrast sensitivity did not significantly correlate with the VF-14 at any of the assessments.

Table 4 Correlations between VF-14 and visual function of the operated eyes (Spearman value rho/p values, significant ${ }^{\star}$ )

\begin{tabular}{lllrl}
\hline & $\begin{array}{l}\text { Preoperative } \\
\text { VF-14 }\end{array}$ & $\begin{array}{l}\text { 3 months } \\
\text { VF-14 }\end{array}$ & $\begin{array}{l}\text { 9 months } \\
\text { VF-14 }\end{array}$ & \multicolumn{1}{l}{$\begin{array}{l}\text { 18 months } \\
\text { VF-14 }\end{array}$} \\
\hline logMAR acuity & $-0.144 / 0.556$ & $-0.034 / 0.894$ & $-0.533 / 0.023^{\star}$ & $-0.608 / 0.007^{\star}$ \\
Contrast sensitivity & $-0.174 / 0.476$ & $0.407 / 0.094$ & $0.435 / 0.071$ & $0.286 / 0.25$ \\
Esterman fields & $0.236 / 0.331$ & $0.398 / 0.102$ & $-0.162 / 0.521$ & $0.627 / 0.005^{\star}$ \\
Stereoacuity & $-0.156 / 0.984$ & $0.021 / 0.935$ & $-0.056 / 0.079$ & $0.627 / 0.000^{\star}$ \\
Mean spherical equivalent & N/A & $0.211 / 0.402$ & $-0.034 / 0.893$ & $0.166 / 0.420$ \\
\hline
\end{tabular}

Correlation was carried out between the unaided visual acuity and contrast sensitivity and the VF-14, since the VF-14 scores for the 3 and 9 months assessments were based on unaided vision. Significant correlation was found only between the 9 months unaided contrast sensitivity and VF-14 (rho $=0.547 / \mathrm{p}$ $=0.019$ ).

Binocular visual field and stereoacuity had significant correlation with VF-14 scores at the 18 months assessment only.

To assess the impact of refractive error (MSE) on the subjective data, Spearman correlations were performed using refraction derived from both the operated and the fellow eye (Spearman values for the fellow eye are not illustrated). There were no significant correlations between VF-14 scores and MSE (data for the operated eye are only quoted).

The VF-14 scores were further categorised into groups based on (a) previous penetrating keratoplasty in the fellow eye, (b) astigmatism, (c) anisometropia ( $>5 \mathrm{D}$ ), and (d) good visual acuity in both eyes (logMAR scores less than 0.2 ).

There was no significant difference in the VF-14 score at any of the assessments when the 18 patients were divided into those who had or had not undergone penetrating keratoplasty in the fellow eye $(p>0.33$ for each assessment, Kruskal-Wallis).

When the patients were divided in to two groups by the level of astigmatism (4D or less and above 4D) there was no significant difference in their subjective visual function score ( $p=0.15$, Mann-Whitney) at any of the assessments. Anisometropia of more than 5D did not have any statistical effect on the VF-14 score ( $p=0.3$, Mann-Whitney).

Patients with good vision in both eyes had significantly better VF-14 scores than those who had poorer vision (acuity greater than 0.2 in both eyes) at the 18 months assessment $(\mathrm{p}=$ 0.014, Mann-Whitney). There were significant correlations between $\log$ MAR visual acuity and contrast sensitivity visual function tests of the fellow eye and the VF-14. For visual acuity, the Spearman values being $-0.697(\mathrm{p}=0.001)$ preoperatively; $-0.742(\mathrm{p}=0.000) 3$ months; -0.551 ( $p=0.018) 9$ months. These significant correlations is to be expected as good visual acuity would give a higher VF-14 score compared with low visual acuity. For contrast sensitivity, the Spearman value reached significance only at 9 months: $0.614(\mathrm{p}=0.007)$.

\section{Discussion}

Penetrating keratoplasty is generally considered to be a successful procedure and the graft clarity rate in keratoconic patients can be as high as $97 \%$ at 4 years. ${ }^{23}$ However, although numerous studies have provided information on visual acuity and refraction following penetrating keratoplasty, only one identified study has described the continual change in visual acuity for a large group of patients. In a retrospective study, Price et $a l^{24}$ found that the visual acuity changed for the better over 5 years following penetrating keratoplasty for a variety of disorders. Our study is the first longitudinal 
prospective report on the continual change from before surgery in a single disease group of technically successful clear corneal grafts using a wide range of visual function variables and a vision specific quality of life questionnaire.

The most important finding of this study is that most aspects of visual function tested and the subjective disability rating improve early on-that is, within the first 3 months after penetrating keratoplasty, and this improvement continues, albeit only slowly. There is significant improvement in visual acuity following surgery and this change continues to be statistically significant between 3 and 9 months but not thereafter. Optical correction was not dispensed until around 1 year after the surgery and therefore both aided and unaided vision has been reported because day to day activities were based on the unaided vision and gave a better representation of functional vision. ${ }^{25} \mathrm{It}$ has been our practice not to correct refractive errors within 3 months of surgery but since visual function changes earlier than this, optical correction could be prescribed earlier which would be reflected in visual function questionnaire scores.

The preoperative contrast sensitivity was reduced compared with normal but improved to normal levels soon after surgery, indicating the beneficial effects of penetrating keratoplasty. Mannis et $a l^{5}$ demonstrated that alterations in contrast sensitivity are associated with keratoconic patients' symptoms of reduced vision even before there was a decrease in visual acuity. They found that following penetrating keratoplasty the contrast sensitivity function at a variety of spatial frequencies improved and patients preferred vision in the eye, which had been grafted even if both eyes had comparable vision. This suggests that visual function is impaired due to the distortion and scarring. Hess and Carney ${ }^{9}$ investigated the effect of induced corneal distortion and found a reduction in high spatial frequencies of contrast sensitivity function, a similar effect to that of keratoconus. Miller and Sanghvi ${ }^{26}$ found that once scarring developed in the keratoconic cornea, all frequencies became attenuated. They recommended that contrast sensitivity testing, with or without a glare source, may be an useful way of following the progression of keratoconus. This has been recommended by a number of clinical guidelines and studies. ${ }^{27-29}$ Since the Pelli-Robson chart measures contrast sensitivity function in the low to mid spatial frequencies ${ }^{16}$ this should pick up changes without the need to test the whole frequency range and could easily and quickly be administered in a clinical setting.

Preoperatively, disability glare produced by the BAT significantly depressed both visual acuity and contrast sensitivity, whereas the decrease in glare postoperatively was not significant. This result concurs with similar improvements following surgery for cataracts. $^{2}{ }^{30}$ The light scattering, which is attributed to corneal distortion and scarring often seen in keratoconus, decreases following penetrating keratoplasty leading to improved visual function. This is consistent with the improvement in vision reported by patients despite a limited visual acuity in the early postoperative period.

In contrast with these findings, however, Carney and Lembach ${ }^{31}$ found that keratoconic patients who had undergone penetrating keratoplasty were more susceptible to glare than those with unoperated keratoconic eyes, while eyes which had undergone epikeratoplasty exhibited the poorest visual performance. However, they did not collect preoperative data and the effect of glare on the operated eyes may well have been more pronounced before penetrating keratoplasty.

The Esterman binocular visual field score did not show any statistically significant change, inferring that keratoconic patients do not have functional impairment of their visual fields. This was unexpected since patients with successful grafts may report improved navigation (personal observation). The anecdotal improvement in visual field reported by patients may be due to the improvement in contrast sensitivity function. Threshold analysis of the central field may yield more information. Faschinger ${ }^{32}$ found that eyes with corneal lattice dystrophy had a general reduction in light sensitivity, an effect also seen in eyes with cataract. Wood et $a l^{33}$ found that the attenuation of the perimetric response arising from cataract was related to the degree of cataract quantified by glare sensitivity, which may well be the case in corneal disease. Another important aspect of an impaired visual field is its effect on the orientation and mobility of the subject. Marron and Bailey ${ }^{34}$ investigated which visual factors affect orientation and mobility and found that contrast sensitivity and visual field had more influence than visual acuity.

The VF-14 questionnaire, which was developed to assess the benefits of cataract surgery, addresses tasks that are dependent on central rather than peripheral vision. This may give an incomplete picture of functional ability that requires good peripheral vision. The only aspect of peripheral vision that is assessed indirectly in the VF-14 is driving. In this study there was marked preoperative impairment in visually dependent tasks, even in such a young group of patients. This confirms that these young patients have significant disability. Following surgery, visual impairment decreased and this trend continued up to the final assessment, when it approached normality.

In a retrospective study of corneal graft recipients, Musch et al ${ }^{35}$ determined the extent of visual disability by administering the VF-14 questionnaire by telephone. They found that at least 1 year after penetrating keratoplasty for a variety of corneal diseases (only 13\% were keratoconic subjects) the mean VF-14 score was 77 , but no data on visual impairment were available before surgery. Their score would be expected to be lower for a number of reasons such as age of the subjects and the presence of macular changes in some cases. Visual disability is further illustrated by the fact that, preoperatively, $90 \%$ of patients had given up driving because of their vision, but at the end of the study period only $54.5 \%$ did not drive. 
In our study two factors, moderate to high anisometropia and astigmatism, which have been thought to cause spectacle intolerance, did not have any impact on subjective visual function scores, concurring with Musch et $a l^{35}$ who did not find any significant correlation between anisometropia and keratometric astigmatism and the VF-14 score. However, Musch et $a l^{35}$ found that when using the SF-36 questionnaire, ${ }^{36}$ which assesses health related quality of life, astigmatism showed a negative association with the patients' social functioning scores. This may be because social functioning requires the recognition of faces. Similarly, Lee et $a l,^{37}$ also using the SF-36, found that blurred vision had a negative impact on functional status.

In the present study, visual acuity significantly correlated with the VF-14 score at 9 and 18 months and the most significant association was at 18 months. This may reflect the fact that patients were wearing some form of refractive correction by then, and their ability to perform visually dependent tasks was improved. Contrast sensitivity did not correlate with the VF-14 scores, probably because the questionnaire was developed to assess acuity based tasks.

Williams et $a l^{11}$ administered a questionnaire to elicit information on patients' opinions as to the success of penetrating keratoplasty 2 years after surgery. The authors found that $75 \%$ of patients were more satisfied with their graft and improvement in their lifestyle if the vision was better than the ungrafted eye. Dissatisfaction was associated with graft failure and the need for contact lens wear. The authors suggested in view of their findings that patients with unilateral diseases were poor candidates for corneal transplantation since it was unlikely they were likely to achieve better vision in the grafted than in the fellow eye. However, distinction needs to be made between satisfaction and change in visual function because unilateral disease may affect binocular function. ${ }^{38} 39$

Williams et $a l^{11}$ also recommended assessment of stereopsis following penetrating keratoplasty. Although in our study analysis of the items in the VF-14 questionnaire that addresses stereopsis did not reach significance there was significant improvement after surgery based on quantitative testing (TNO test).

In view of our findings, we feel that further prospective studies are needed to ascertain the benefits of penetrating keratoplasty in unilateral diseases taking into account ocular dominance and to assess visual outcome as early as 1 month postoperatively. Since this study was initiated, a specific instrument to assess visual disability in keratoconus (CLEK-VFQ) ${ }^{40}$ has been developed and could be used in future studies.

In summary, both visual function and vision specific health status improved within 3 months of penetrating keratoplasty. For keratoconic patients, who tend to be young and in their most productive years, corneal transplantation can offer rapid visual rehabilitation. Although visual acuity remains important in routine visual assessment, other variables give a more global picture of visual function.
Increasingly, the benefits of surgical procedures and change in visual status are being assessed using a wide range of methods, which will help surgeons in the selection of patients and in the measurement and prediction of outcome.

The authors would like to thank the contributions of the following individuals: Dr Brian Farragher, medical statistician, Department of Medical Computation, University of Manchester, Gill Dean, Visual Fields Service, Department of Optometry, Royal Eye Hospital, Manchester.

The study was performed at the Royal Eye Hospital, Manchester and was funded by the North Western Regional Health Authority Reactive Funding Scheme, grant no RF 14.

1 Vail A, Gore SM, Bradley BA, et al. On behalf of Corneal Transplant Follow-up Study Collaborators. Corneal graft survival and visual outcome: a multicentre trial. Ophthalmology 1993;101:120-7.

2 Rubin GS, Adamsons IA, Stark WJ. Comparison of acuity, contrast sensitivity, and disability glare before and after cataract surgery. Arch Ophthalmol 1993;111:56-61.

3 Bodis-Wollner I. Detection of visual defects using the contrast sensitivity function. Int Ophthalmol Clin 1980;20: $135-53$.

4 Elliot DB, Hurst MA, Weatherill J. Comparing clinical tests of visual function in cataract with the patient's perceived
visual disability. Eye 1990;4:712-17.

5 Mannis MJ, Zadnik K, Johnson CA. The effect of penetrating keratoplasty on contrast sensitivity in keratoconus. Arch ing keratoplasty on contrast sensiti

6 Bernth-Petersen P. Visual functioning in cataract patients: methods of measuring and results. Acta Ophthalmol 981;59:198-205

7 Applegate WB, Miller ST, Elam JT, et al. fAMA 1987;257: $1064-6$

8 Mannis MJ, Zadnik K, Johnson CA, et al. Contrast sensitivity after penetrating keratoplasty. Arch Ophthalmol 1987; 105:1220-3.

9 Hess RF, Carney LG. Vision through an abnormal cornea: a pilot study of the relationship between visual loss from corneal distortion, corneal edema, keratoconus, and some

10 Carney LG. Visual loss in keratoconus. Arch Ophthalmol 1982;100:1282-5.

11 Williams KA, Ash JK, Pararajasegaram P, et al. Long-term outcome after corneal transplantation: visual results and patient perception of success. Ophthalmology 1991;98:65185.

12 Armitage WJ, Moss SJ, Easty DL, et al. Supply of corneal tissue in the United Kingdom. Br F Ophthalmol 1990;74: $685-7$.

13 Doyle SJ, Harper C, Marcynuik B, et al. Prediction of refractive outcome in penetrating keratoplasty for keratoconus. Cornea 1995;15:441-5.

14 Ferris FL, Kassoff A, Bresnick GH, et al. New visual acuity charts for clinical research. Am f Ophthalmol 1982;94:91-6.

15 Bailey IL, Bullimore MA, Raasch TW, et al. Clinical grading and the effects of scaling. Invest Ophthalmol Vis Sci 1991;32:422-32

16 Pelli DG, Robson JG, Wilkins AJ. The design of a new letter chart for measuring contrast sensitivity. Clin Vis Sci 988;2:187-99.

17 Elliot DB, Bullimore MA. Assessing the reliability, discriminative ability, and validity of disability glare tests. Invest Ophthalmol Vis Sci 1993;34:108-19.

18 Clement Clarke International Ltd. The Pelli-Robson Chart instructions. Harlow, Essex: CCI, 1989.

19 Holladay JT, Trujillo J, Prager TC, Ruiz RS. Brightness acuity test (BAT) and outdoor visual acuity in cataract patients. F Cataract Refract Surg 1987;13:67-9

20 Esterman B. Functional scoring of the binocular field. Ophthalmology 1982;89:1226-34.

21 Walraven J. Amblyopia screening with random-dot stereograms. Am 7 Ophthalmol 1975;80:893-900.

22 Steinberg EP, Tielsch JM, Schein OD, et al. The VF-14: an index of functional impairment in patients with cataract. Arch Ophthalmol 1994;112:630-8.

23 Kirkness CM, Ficker LA, McG Steele AD, et al. The success of penetrating keratoplasty for keratoconus. eye 1990;4: 673-88

24 Price FW, Whitson WE, Marks RG. Progression of visual acuity after penetrating keratoplasty. Ophthalmology 1991; 98:1177-85.

25 Koenig SB, McDermott ML, Hyndiuk RA. Penetrating keratoplasty and intraocular lens exchange for pseudophakic bullous keratopathy associated with a closed loop anterior chamber intraocular lens. Am f Ophthalmol 1989;108: $43-8$.

26 Miller D, Sanghvi S. Contrast sensitivity and glare testing in corneal disease. In Nadler MP, Miller D, Nadler DJ, eds. Glare and contrast sensitivity for clinicians. New York: Springer-Verlag, 1990:45-52.

27 American Academy of Ophthalmology. Committee on Ophthalmic Procedures Assessment. Contrast sensitivity Ophthalmic Procedures Assessment. Contrast sensitivity
and glare testing in the evaluation of anterior segment disease. Ophthalmology 1990;97:1233-7. 
28 Marmor MF, Gawande A. The effect of blur on contrast sensitivity: clinical implications. Ophthalmology 1988;95. sensitivity:

29 Moseley MJ, Hill AR. Contrast sensitivity in clinical practice. Br F Ophthalmol 1994;78:795-7.

30 Adamsons IA, Vitale S, Stark WJ, et al. The association of postoperative subjective visual function with acuity, glare and contrast sensitivity in patients with early cataract. Arch Ophthalmol 1996;114:529-36.

31 Carney LG, Lembach RG. Management of keratoconus: comparative visual assessments. CLAO f 1991;17:52-8.

32 Faschinger C. Computer perimetry in patients with corneal dystrophies. Doc Ophthalmol Proc Ser 1987;49:61-4.

33 Wood JM, Wild JM, Smerdon DL, et al. Alterations in the shape of the automated perimetric profile arising from cataract. Graefes Arch Clin Exp Ophthalmol 1989;227:157cataract

34 Marron JA, Bailey IL. Visual factors and orientationmobility performance. Am F Optom Physiol Opt 1982;59: mobility
35 Musch DC, Farjo AA, Meyer RF, et al. Assessment of health-related quality of life after corneal transplantation. Am F Ophthalmol 1997;124:1-8.

36 Ware JE, Sherbourne CD. The MOS 36-item short-form health survey (SF-36): I. Conceptual framework and item selection. Med Care 1992;30:473-83.

37 Lee PP, Spritzer K, Hays RD. The impact of blurred vision on functioning and well-being. Ophthalmology 1997;104: on functic

38 Pardhan S, Gilchrist J. The effect of monocular defocus on binocular contrast sensitivity. Ophthal Physiol Opt 1990;10: 33-6.

39 Pardhan S, Gilchrist J. Binocular contrast sensitivity with monocular glare disability. Ophthal Physiol Opt 1990;10: 37-9.

40 Zadnik K, Barr JT, Edrington TB, et al. Baseline findings in the Collaborative Longitudinal Evaluation of Keratoconus (CLEK) Study. Invest Ophthalmol Vis Sci 1998;39:2537-46. 